\title{
NUMERICAL INVESTIGATIONS OF ELECTRIC HEATING IMPACTS ON SOLID/LIQUID GLASS FLOW PATTERNS
}

\author{
S.L. Chang, C.Q. Zhou* and B. Golchert \\ Argonne National Laboratory \\ Argonne, IL 60439 USA \\ slchang@anl.gov \\ *Purdue University Calumet \\ Hammond, IN 46323 USA
}

\begin{abstract}
A typical glass furnace consists of a combustion space and a melter. Intense heat is generated from the combustion of fuel and air/oxygen in the combustion space. This heat is transferred mainly by radiation to the melter in order to melt sand and cullet (scrap glass) eventually creating glass products. Many furnaces use electric boosters to enhance glass melting and increase productivity. The coupled electric/combustion heat transfer patterns are key to the glass making processes. The understanding of the processes can lead to the improvement of glass quality and furnace efficiency. The effects of electrical boosting on the flow patterns and heat transfer in a glass melter are investigated using a multiphase Computational Fluid Dynamics (CFD) code with addition of an electrical boosting model. The results indicate that the locations and spacing of the electrodes have large impacts on the velocity and temperature distributions in the glass melter. With the same total heat input, the batch shape (which is determined by the overall heat transfer and the batch melting rate) is kept almost the same. This indicates that electric boosting can be used to replace part of heat by combustion. Therefore, temperature is lower in the combustion space and the life of the furnace can be prolonged. The electric booster can also be used to increase productivity without increasing the furnace size.
\end{abstract}

$\begin{array}{ll}\text { NOMENCLATURE } \\ \mathrm{d} & \text { empirical film thickness }(\mathrm{m}) \\ \mathrm{D} & \text { particle diameter }(\mathrm{m}) \\ \mathrm{g} & \text { gravitational acceleration }\left(\mathrm{m} / \mathrm{s}^{2}\right) \\ \mathrm{h}_{\mathrm{m}} & \text { heat of melting } \\ \mathrm{k} & \text { thermal conductivity }(\mathrm{w} / \mathrm{m} / \mathrm{K}) \\ \mathrm{n} & \text { particle number density }\left(\# / \mathrm{m}^{3}\right) \\ \mathrm{p} & \text { pressure }(\mathrm{Pa}) \\ \mathrm{q}_{\mathrm{c}} & \text { film conduction heat flux }\left(\mathrm{J} / \mathrm{m}^{2}\right)\end{array}$

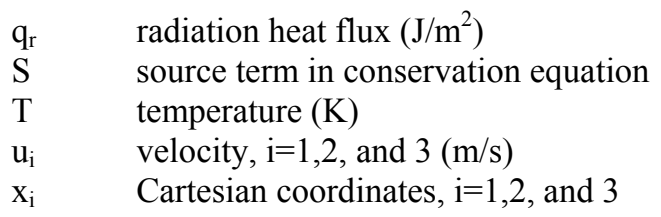

\section{Greek Symbols}

$\Gamma \quad$ diffusivity $\left(\mathrm{m}^{2} / \mathrm{s}\right)$

$\kappa \quad$ compressibility $(\mathrm{Pa})$

$\mu \quad$ viscosity (Pa-s)

$\theta \quad$ volume fraction

$\rho \quad$ density $\left(\mathrm{kg} / \mathrm{m}^{3}\right)$

$\xi \quad$ general flow property $\left(1, \mathrm{u}_{\mathrm{i}}\right.$, and $\left.\mathrm{h}\right)$

\section{Subscripts \\ $\mathrm{p} \quad$ particle \\ m melting}

\section{INTRODUCTION}

Rapid advances in computer speed and memory have made possible a concurrent advance in numerical analyses of complex combustion systems of practical interest. One of such systems is a glass furnace that consists of a combustion space, a glass-melting tank (melter), and a glass holding tank (refiner). In the furnace, the intense heat (mainly radiation) from the combustion of fuel and air/oxygen is used to melt sand and cullet (scrap glass) into liquid glass before forming final products such as pane glass, TV glass, and etc. Liquid glass is extremely viscous at low temperatures and glass quality suffers when low temperature spots exist in a melter. Many furnaces use electric boosters in the glass melt to enhance glass melting and increase productivity. Electric boosting can also supplement the fossil fuel used for combustion with electrical energy supplied by the electrodes. The coupled electric/combustion heat transfer patterns are key to the glass making processes. The understanding of the processes can lead to the improvement of glass quality and furnace efficiency. 
Since the melting of glass is energy intensive, an improvement in the performance (efficiency) of a glass furnace can save energy and reduce the emissions of pollutants (NOx and particulates) and greenhouse gas $\left(\mathrm{CO}_{2}\right.$ and $\left.\mathrm{H}_{2} \mathrm{O}\right)$. Many chemical and physical processes proceed simultaneously in a glass tank. The important technical aspects for the design and the construction of a glass tank are the final glass quality, the tank lifetime, the efficiency of glass feed melting, low pollutant emissions, and the flexibility of the system. These aspects are largely determined by the hydrodynamics of both liquid glass and solid batch flows. Proper modeling of the flow patterns of the solid batch and liquid glass are key to determining the glass quality, furnace efficiency and emissions.

Recently, the glass industry recognizes that computational fluid dynamics (CFD) simulation can be an important tool to help improve the performance of glass furnaces. CFD simulations are being used as a tool to analyze flow characteristics of a glass furnace and find ways to improve the energy efficiency and reduce pollutant emissions. CFD codes have been used to model the combustion space (May and Kremer, 1999, Chang, et al., 2000) and the glass-melt flow (Viskanta, 1994, Kawachi and Iwatsubo, 1999) of a glass furnace, respectively. The early studies found that the flow fields of the combustion space and glass melt region strongly interact with each other. The radiation heat transfer from the combustion space drives the glass melt flow through the melting of the batch and the heating of the liquid glass and a significant portion of the spectra of the radiation can penetrate into the glass flow. Therefore, the coupling of the combustion space and glass melt flows is essential for a realistic modeling of a glass furnace. Recently, preliminary coupled glass furnace simulations have been attempted (Schnepper, et.al. 1997, Hoke and Marchiando 1998). These preliminary attempts included weak coupling of the interface with heat balance.

A consortium of glass companies, universities, and Argonne National Laboratory (ANL) was formed to develop a rigorous, coupled glass furnace simulation. The simulation will include important coupling issues such as batch melting, foam coverage, and radiation penetration. ANL's coupled simulation also includes a comprehensive treatment of radiation heat transfer and pollutant emission model. This paper focuses on the development of a multiphase CFD code for the simulation of solid and liquid glass flows in a glass melter. This paper focuses on the impacts of electric heating patterns on the solid and liquid glass flows in the melter. The technical approach and the results are presented in the following sections.

\section{TECHNICAL APPROACH}

\section{Glass Furnace Model (GFM)}

A glass furnace model (GFM) has been developed which includes three major component models: (1) combustion flow, (2) radiation heat transfer, and (3) glass melt flow (Chang et al. 2000, 2001). The overall simulation is an iterative procedure that uses a radiation heat transfer calculation to couple the flow simulations of the combustion space and the melter. The glass flow simulation and the electric booster model are described in the following.

\section{Simulation of Glass Melt Flow}

The Eulerian approach is used for both the solid and the liquid flows. The glass flow is driven by the radiation heat transfer from the combustion space. The radiation heat flux on the glass surface is obtained from separate calculations of the combustion flow and radiation heat transfer. The surface heat flux is used as an input to the glass-melt flow code to calculate local temperature, velocity, height, and melting rate of the batch, as well as local temperature and velocity of the liquid glass.

\section{$\underline{\text { Solid Batch Flow }}$}

In the Eulerian approach, batch particles are divided into a number of size groups and particles of a size group are treated as a continuum so conservation equations of mass, momentum, and energy can be derived. The source and sink terms of the conservation equations are derived from phenomenological models such as batch melting, interfacial drag and heat transfer, solid pressure and other models.

The mass, momentum, and energy conservation equations of the batch flow are used to solve for local batch particle number density, velocity, and temperature. The conservation equation of solid mass (or number density) for a size group $\mathrm{k}$ is derived as,

$$
\sum_{\mathrm{i}=1}^{3} \frac{\partial}{\partial \mathrm{x}_{\mathrm{i}}}\left(\mathrm{n}_{\mathrm{k}} \mathrm{u}_{\mathrm{i}, \mathrm{p}, \mathrm{k}}\right)=\mathrm{S}_{\mathrm{n}}
$$

in which, $n_{k}$ is particle number density, $x_{i}, i=1,3$ are coordinates, $\mathrm{u}_{\mathrm{i}, \mathrm{p}, \mathrm{k}}$ is particle velocity, $\mathrm{S}_{\mathrm{n}}$ is the source term. Particles start to melt when their temperature reach the melting point. The melting process shifts particles to a smaller size group. The shifting produces a sink term for the size group, a source term for the smaller size group, and a source term for the liquid glass.

The solid momentum and energy equations of a particle size group $\mathrm{k}$ can be derived as,

$$
\sum_{i=1}^{3} \frac{\partial}{\partial x_{i}}\left(n_{k} u_{i, p, k} \xi-\Gamma_{\xi} \frac{\partial n_{k} \xi}{\partial x}\right)=S_{\xi}
$$


in which, $\xi$ is particle general property, representing a particle velocity component, or particle temperature, $\Gamma$ is diffusivity, and $\mathrm{S}$ is the source term. Interfacial drag and heat transfer models are needed to generate source terms for the momentum and energy equations.

\section{Liquid Glass-Melt Flow}

It is assumed that the glass-melt is a Newtonian fluid and the flow is laminar and steady state. For the liquid glass-melt flow, the flow properties needed to determine the state of the flow system and to evaluate its performance are pressure, density, temperature, and velocity components. The properties can be solved from the conservation equations of mass, momentum, and energy, and equations of state.

The conservation equations of the liquid flow can be arranged in a common form, Eq. (3).

$$
\sum_{\mathrm{i}=1}^{3} \frac{\partial}{\partial \mathrm{x}_{\mathrm{i}}}\left(\rho \mathrm{u}_{\mathrm{i}} \xi-\Gamma_{\xi} \frac{\partial \xi}{\partial \mathrm{x}_{\mathrm{i}}}\right)=\mathrm{S}_{\xi}
$$

in which $\xi$ is a general liquid glass flow property, $\mathrm{u}_{\mathrm{i}}$, $\mathrm{i}=1,3$ are velocity components, $\Gamma_{\xi}$ is diffusivity, and $\mathrm{S}_{\xi}$ is the sum of source terms. The general flow property represents a scalar, a velocity component, or an enthalpy for the mass, momentum, and energy equations, respectively. Density, viscosity, and thermal conductivity are functions of temperature (Stanek, 1977).

\section{Phenomenological Models}

Phenomenological models are used to characterize multiphase flow characteristics in the glass melter including solid pressure, interfacial drag and heat transfer, buoyancy, and batch melting. The buoyancy force, solid pressure, and drag force are the source terms for the solid momentum equation. The drag force is also a sink term of the liquid momentum equation. The radiation heat flux is a source term in the solid energy equation in the batch coverage area and is a source term in the liquid energy equation outside the batch coverage area. On the bottom side of the batch, it is assumed that the batch will melt into liquid glass in a thin film. The film conduction heat flux is a sink term of the liquid energy equation.

The batch-melting model is derived based on the assumption that when the batch temperature reaches the melting temperature, the temperature remains at the melting temperature. Particles shift to a smaller size group during the melting process. The radiation melting occurs on the topside of the batch and the film conduction melting occurs on the bottom side of the batch. The batch-melting rate is equal to the ratio of the sum of radiation and film conduction heat fluxes to the heat of melting. The melting rate is a source term of the liquid mass equation and a sink term of the solid mass equation. The melting also shifts the batch particles from a larger size group to a smaller size group. The shift rate is calculated based on local particle number density. Batch coverage is determined from local particle number density and velocity. The details of the phenomenological models can be found in previous publications (Chang et al. 2000 and 2001)

\section{Electric Booster Model}

Immersing electrodes into the glass melt and connecting the electrodes to an electric power source achieve electric boosting in glass furnaces. The electrodes are usually rod- or disk-type. By imposing differences in potential among electrodes, an electric potential field is generated in the melter because the liquid glass is an electrically conductive medium (Stanek, 1977). The electric current in the liquid glass creates the Joulean heating. Local Joulean heat flux $\mathrm{q}_{\mathrm{e}}$, a source term for the energy equation of the liquid flow, can be calculated from the following equations.

$$
\phi_{\mathrm{e}}=\mathrm{jE}
$$

in which $E$ is the electric potential $(\mathrm{V} / \mathrm{m})$ and $\mathrm{j}$ is the electric current $\left(\mathrm{A} / \mathrm{m}^{2}\right)$.

The electric potential $\mathrm{E}(\mathrm{V} / \mathrm{m})$ is described by Maxwell's equation:

$$
\text { Let } \begin{gathered}
\nabla \times \mathrm{E}=0 \\
\mathrm{E}=-\nabla \mathrm{V}
\end{gathered}
$$

in which $\mathrm{V}$ is electric potential energy (V) that satisfies Maxwell equation automatically.

The conservation of electric current $\mathrm{j}\left(\mathrm{A} / \mathrm{m}^{2}\right)$ is given as:

$$
\nabla \bullet \mathrm{j}=0
$$

From the Ohm's law:

$$
\mathrm{j}=\sigma \mathrm{E}
$$

in which $\sigma$ is electric conductivity $(1 / \mathrm{ohm}-\mathrm{m})$, which is dependent on the temperature of glass-melt.

\section{NUMERICAL SCHEME}

The CFD code uses a control volume approach to convert the governing equations to algebraic equations on a discretized grid system. The grid system is staggered and consists of four grids: one for each of the three momentum component directions of the liquid phase momentum equations, and a scalar grid for all the other equations. The algebraic equations are solved iteratively with the boundary conditions. There are two major iteration routines in the multiphase flow 
simulation. The first is for the liquid glass flow calculation, and the second is for the solid batch flow calculation. In the calculations of liquid-phase equations, Patankar's SIMPLER computational scheme (Patankar, 1980) is used to solve the pressure linked momentum and continuity equations.

In order to conserve computational time and still provide adequately accurate results, grid sensitivity studies were conducted to choose suitable grids that gave grid-independent numerical results to three significant decimal digits upon further grid refinement. An important feature of the control volume approach used in the computational scheme is that it is conservative in terms of mass, energy, species, and all variables solved for via the transport equations, both locally and globally, to a very high degree regardless of grid size. This feature helps to ensure that results are physically realistic regardless of grid size and that trends in parametric studies are much less sensitive to grid size. For the purposes of the current study, little would be gained from attempting to refine the grid to make results grid independent to more than three or four significant digits.

\section{RESULTS AND DISCUSSION}

\section{Code Validation}

All the CFD codes used in the glass furnace simulations were validated using several sets of experimental data obtained from an industrial glass furnace. This furnace is approximately $18 \mathrm{~m}$ long, 7 $\mathrm{m}$ wide, and $4 \mathrm{~m}$ deep $(3 \mathrm{~m}$ in the combustion space and $1 \mathrm{~m}$ in the glass melt). The furnace operated with four pairs of staggered natural gas/oxygen diffusion burners. Two exhausts were located on each side of the furnace. Six screw feeders insert batch materials onto the molten glass. The molten glass leaves the furnace through a throat located at the bottom of the glass melt on the wall opposite the screw feeders.

For proprietary reasons, the actual measured values cannot be presented. For an overview of the measurement campaign and some representative numbers, see (Cook et al., 2000). The measurement campaign obtained spatial values for gas temperature, gas species concentration, gas velocities, glass surface temperatures, glass surface velocities, wall temperatures, and directional radiation heat fluxes. The glass company provided detailed operating conditions so that simulations of the furnace could be created for validation of the codes.

Comparisons between the simulation results and the measurements indicate good agreement with regard to most of the measured quantities. Calculated gas temperature, gas velocity, gas composition, glass surface temperature, and wall temperature calculations matched the measured values within the error bounds of the measured values. Directional radiation heat flux calculations compare favorably with respect to the magnitude of the heat flux. In addition, the computed heat fluxes followed the ordering of the measured heat fluxes. By ordering, it is meant that the directional dependence of the measured heat flux is reflected in the computed results (Golchert et al. 2001).

\section{Melter Flow Characteristics}

Simulations were developed for a commercial scale glass furnace. Figure 1 shows the schematic of the glass melter. There are six batch inlets (charge end) and one exit. Flow property distributions were computed and are shown from three different views (top, side, and end). The top view is at the glass surface ( $x-z$ plane). The side view is the verticallongitudinal plane ( $x-y$ plane). The end view is the vertical-span wise plane (y-z plane). The actual numbers on the figures are not shown to protect proprietary information.

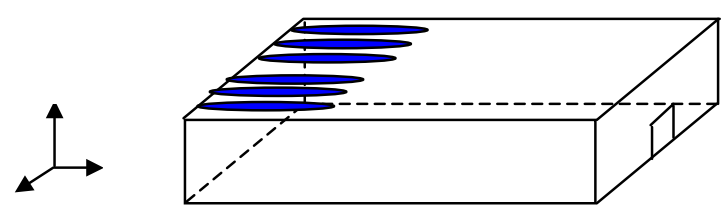

Figure 1 Schematic of Glass Melter

Figures $2 \mathrm{a}, 2 \mathrm{~b}$, and $2 \mathrm{c}$ show the top view of the computed batch melting rate, liquid glass temperature and velocity vectors, and batch particle number density of the glass melt flow on the melter surface, respectively. A uniform radiation heat flux from combustion space was assumed for these calculations. In all the figures, the dark color represents the highest value and the light color represents the lowest value as shown in the scale.

Figure $2 \mathrm{a}$ shows the batch melting rate distribution. In the figure, six batch lines are clearly shown by high melting rates. Figure $2 \mathrm{~b}$ shows glass temperature and velocity vectors on the melter surface. The temperatures are highest near the exit of the melter and lower near the inlet of the batch. The low temperature regions indicate the batch coverage areas, which are also displayed very clearly in batch number density distributions as shown in Figure 2c. On the melter surface, a strong back flow appears that brings molten glass at higher temperatures from the exit region to the batch inlet. This hotter glass flows underneath the batch coverage providing the additional 
energy needed for melting the batch other than radiation heat flux on the surface.

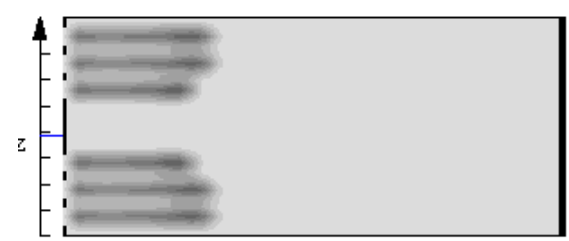

(a) Melting Rate

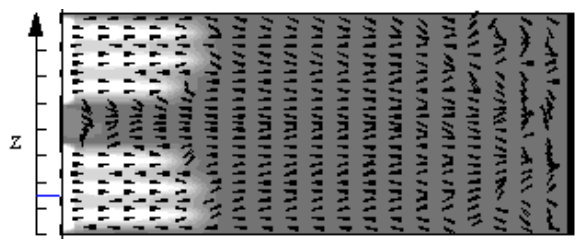

(b) Glass T \& V

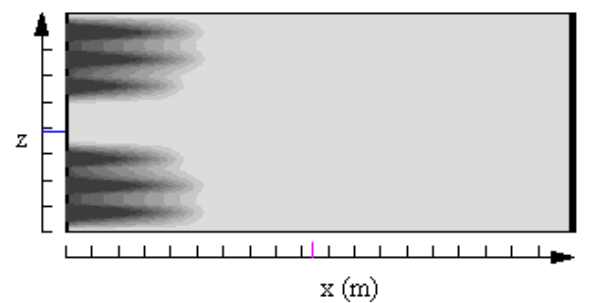

charger end

(c) Batch Number Density

exit

Figure 2 Computed Glass Properties on the Melter Surface

Figure 3 shows glass temperature and velocity vectors in vertical-longitudinal planes (side view) at three different locations $(\mathrm{z} 1<\mathrm{z} 2<\mathrm{z} 3)$. Figure $3 \mathrm{a}$ is the vertical plane through a batch inlet. The low temperature region again shows the batch coverage area. Figure $3 \mathrm{~b}$ is the vertical plane between a batch inlet and the center. Figure $3 \mathrm{c}$ is the vertical plane through the center of the glass melter, where the exit is located. All these side views show clearly that temperature decreases from the top to the bottom of the glass melter. At the glass surface, the temperature is the highest because of the radiation heat flux from the combustion space incident upon the surface. At the bottom of the glass melter, temperature is the lowest due to the heat loss through the wall and the melting of the solid batch. Since a glass melter is relatively shallow in its depth compared with its length, the temperature gradients in the vertical direction are much larger in comparison to the other two directions. It is also clear that temperature gradients near the inlet are larger than those near the outlet because of the cold solid batch.

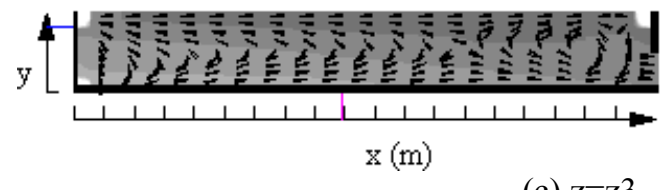

(c) $\mathrm{z}=\mathrm{z} 3$

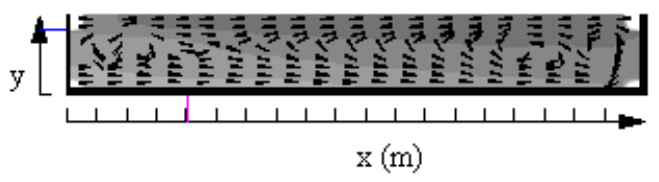

(b) $\mathrm{z}=\mathrm{z} 2$

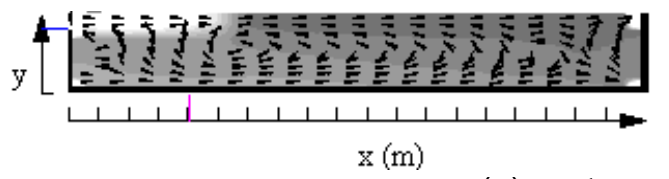

(a) $\mathrm{z}=\mathrm{z} 1$

Figure 3 Side View of Glass Temperature and Velocity

The velocity vectors from the side views of the glass flow show various vortices. The viscosity of the glass in the melter is a strong function of temperature, and consequently variations in temperature distribution can have a relatively large influence on the flow patterns of glass, which affect both the flow pattern of the batch and heat transfer to the batch for melting. At high temperature regions near the glass surface, viscosity decreases significantly, which allows the melt to flow easily away from the hot region. The lower viscosity combined with the temperature gradient near the surface is the major driving force for the recirculations in the melter. The recirculation zones are stronger at the regions with higher temperature gradients. The recirculation and glass flow patterns are important in understanding the overall melting process in the furnace. A strong recirculation zone under the batch is desirable for the melting process, because it homogenizes the glass melt. By homogenization, it is meant that the glass has time to properly mix, to remove unwanted gaseous bubbles, and to melt undesired solid grains. The flow pattern also shows that velocity is the highest on the top surface due to the higher temperature and the lowest at the cold bottom of the melter.

Glass temperature and velocity vectors in verticalspan wise planes $(\mathrm{x} 1<\mathrm{x} 2<\mathrm{x} 3)$ are shown in Figure 3 (end view). Buoyancy-driven convective flow of multiple cells is clearly revealed. The circulation cells are caused by the temperature gradient along the span direction. The velocity vectors from both side and end views of the glass flow show very complex threedimensional flow patterns. Figure $4 \mathrm{a}$ is the end view near the middle of the batch. Again, six batch regions are clearly indicated by their low temperatures. 
Temperature gradients are very large due to the cold batch. Temperature is more uniform further downstream as shown in Figures $4 \mathrm{~b}$ and $4 \mathrm{c}$.

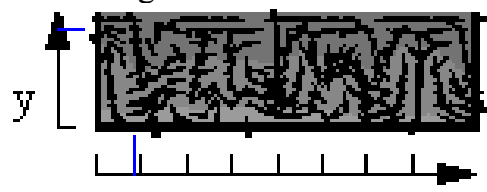

$z$ $\mathrm{x}=\mathrm{x} 3$

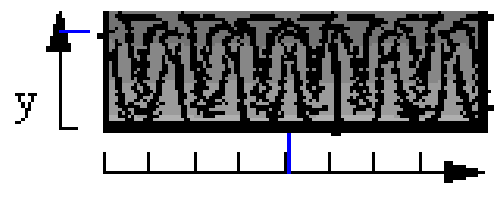

$z$ $\mathrm{x}=\mathrm{x} 2$

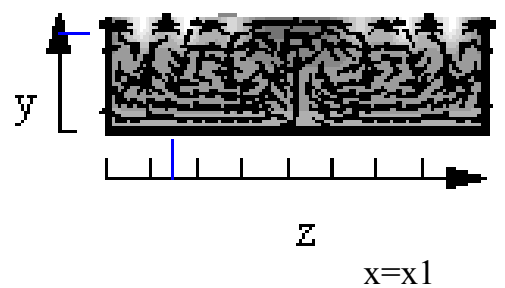

Figure 4 End View of Glass Temperature and Velocity

\section{Effects of Electrical Boosting}

To investigate the effects of electric booster on the flow pattern and heat transfer to the glass-melt, five cases were considered. These cases have electric booster with varied spacing and locations of electrodes. All the electrodes are inserted from the bottom of the melter and five pairs of rod-type electrodes are used.

Figure 5 shows the electric potential for the five cases at $x-y$ and $x-z$ planes. Again, the dark color represents a high value and the light color indicates a low value. All the figures have the same scale and five pairs of electrodes are used. These will be all the same for all of the remaining figures in the following sections. The locations of the electrodes are indicated clearly. All five cases receive total heat of 6.3 MW. Cases (a), (b) and (c) receive 4.5 MW of combustion heat and 1.8 MW of the electric booster heat. The arrangements of electrodes are the same. The locations of electrodes, however, are different. The electrodes are located near the batch inlet in case (a) and further downstream in cases (b) and (c) respectively. Case (d) receives $5.4 \mathrm{MW}$ of combustion heat and $0.9 \mathrm{MW}$ of the electric booster heat. Case (e) receives 4.1 MW of combustion heat and 2.2 MW of the electric booster heat.
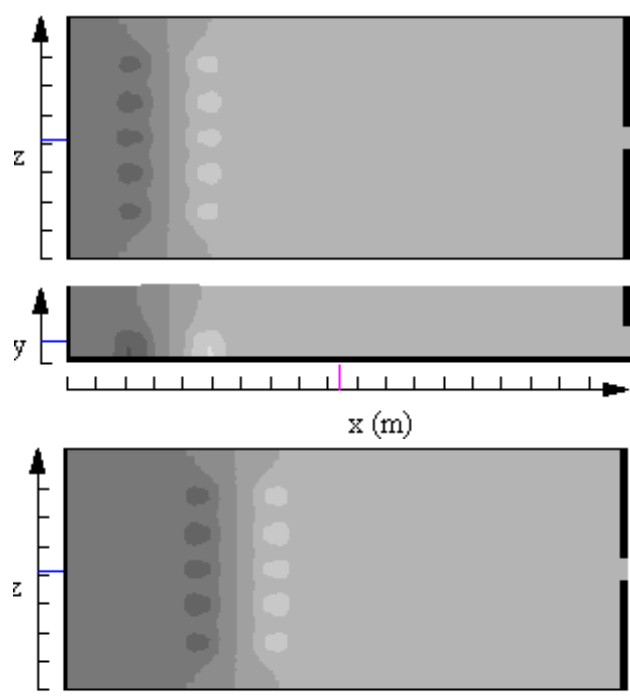

(a)

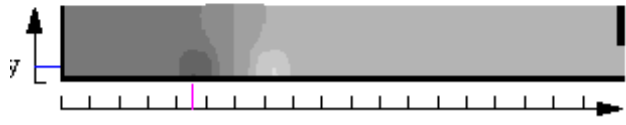

$\mathrm{x}(\mathrm{m})$

(b)
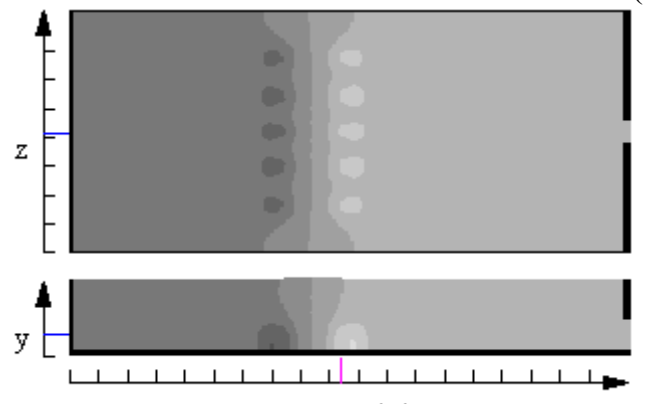

$\mathrm{x}(\mathrm{m})$

(c)
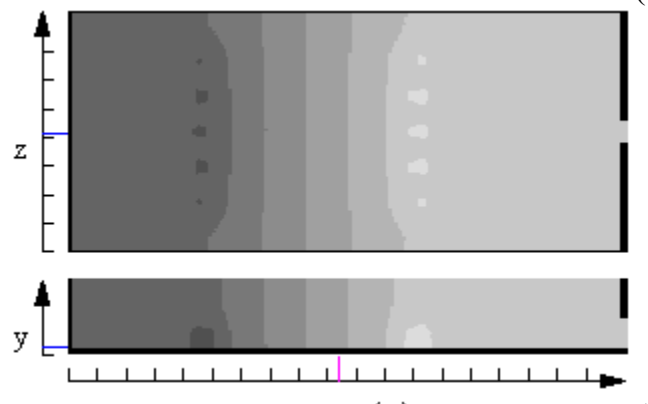

$\mathrm{x}(\mathrm{m})$
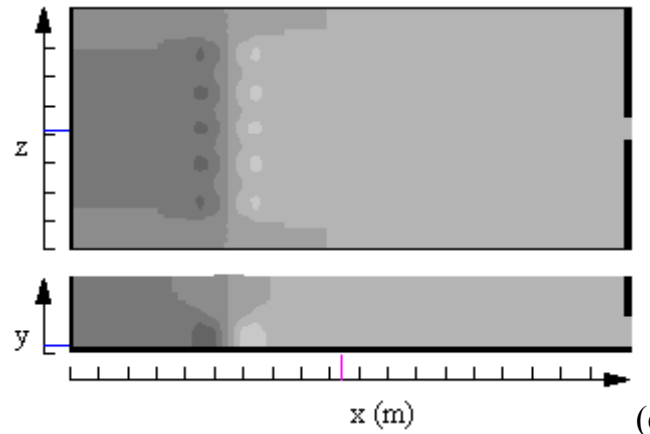

Figure 5 Electrical Potential Distributions 
Figure 6 shows the electric (Joule) heat for the five cases at $\mathrm{x}-\mathrm{y}$ and $\mathrm{x}-\mathrm{z}$ planes. Velocity vectors are also plotted in the $x-y$ plane (side view). The figures indicate clearly the electric heat generated by the electrodes. However, the distributions are strongly affected by the location. This is because the electric conductivity is dependent on the glass temperature. At different location, the temperature is different. Therefore, the electric heat generated is different. The spacing between a pair of the electrodes also has large impact on the generation of electric Joule heat, because the electric potential field is directly related to the spacing. The velocity vectors in Figure 6 also displays that the flow patterns is affected by the location of electrode and consequently the temperature will be affected.
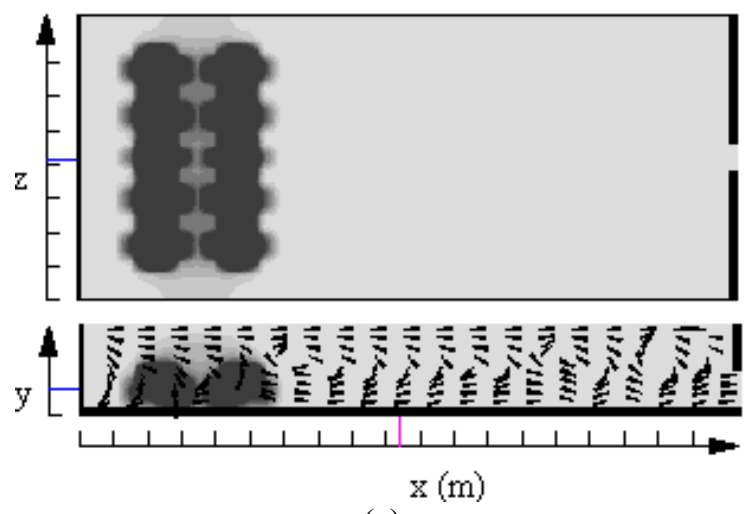

(a)
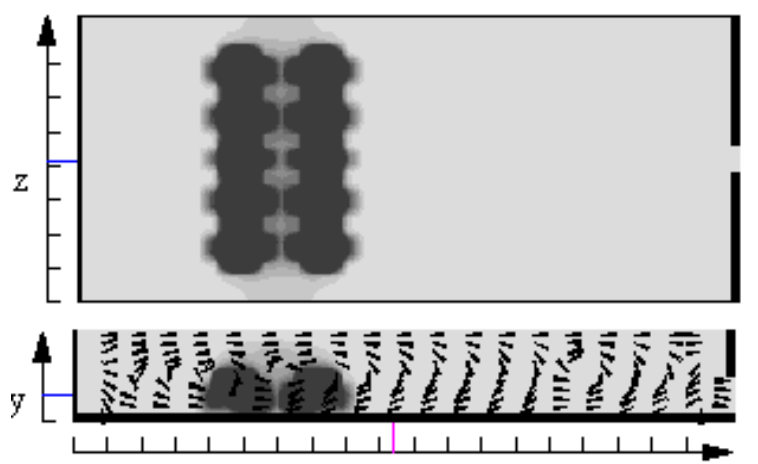

$\mathrm{x}(\mathrm{m})$

(b)

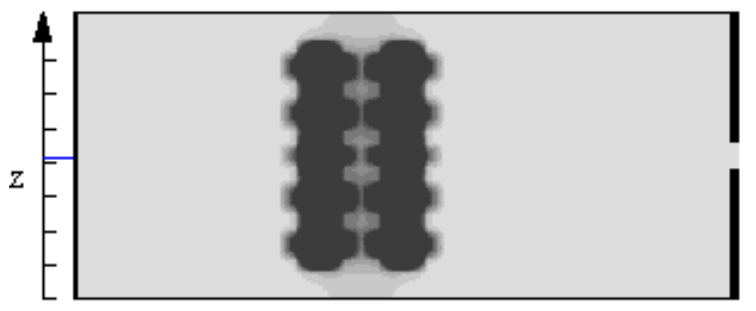

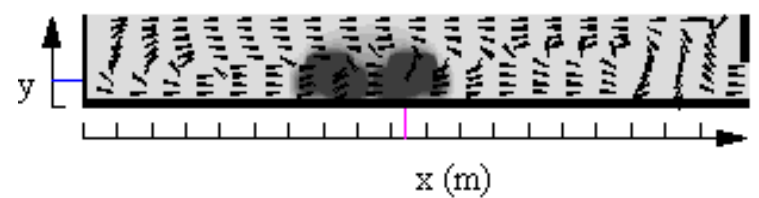

(c)
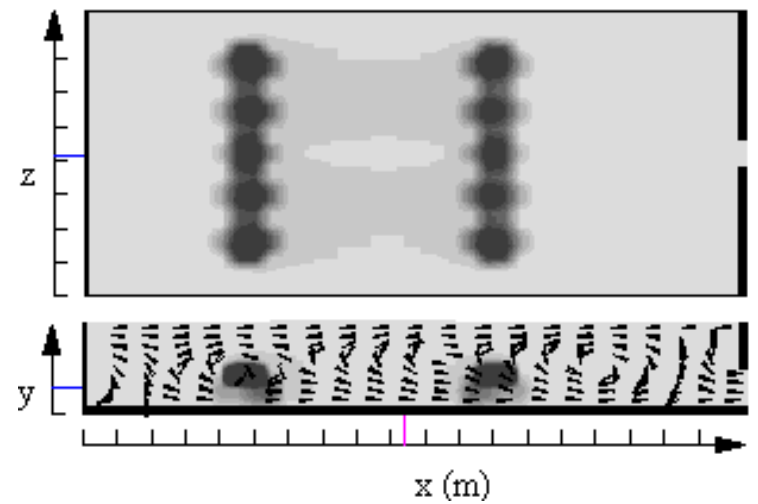

(d)
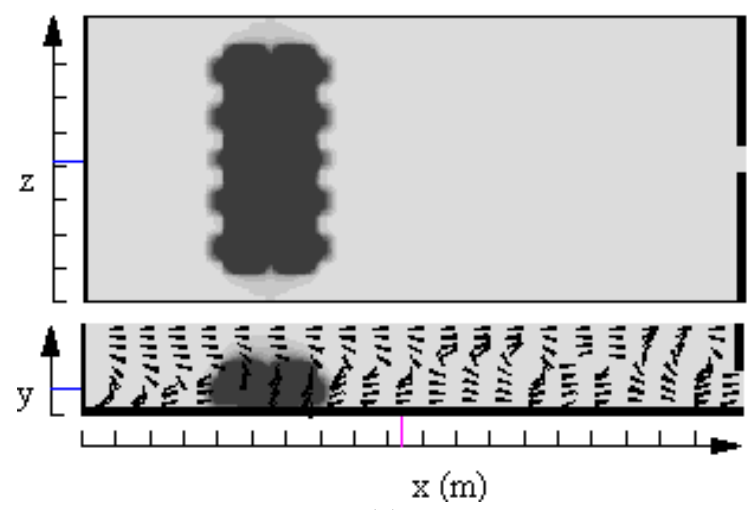

(e)

Figure 6 Electric (Joule) Heat and velocity Distributions

Figure 7 shows temperature field in the $x-y$ plane (side view) for all the five cases. In addition, a case that receives only combustion heat of $6.3 \mathrm{MW}$ is also shown in Figure 7(f) for comparison. Cases (a), (b), and (c) show that the heat transfer is affected by the locations of the electrodes. Cases (d), (e), and (f) demonstrate strong effects of the percentage of heat provided by the electrodes on the temperature distribution. The temperature is more uniform along the depth of the meter (y-direction) at the location of electrodes because of heat generated by the electrodes.

In all these cases, the melting rate distributions are not affected significantly because the total heat input is the same for all cases (see Figure 8). This indicates that the electric boosting may be used to replace part of heat provided by combustion. Therefore, temperature is lower in the combustion space and the 
life of the furnace can be prolonged. The electric boosting can also be used to increase the productivity without increasing the furnace size.

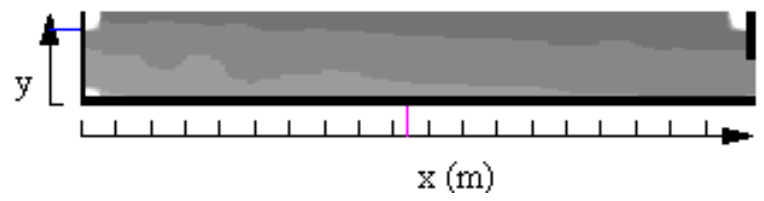

(a)

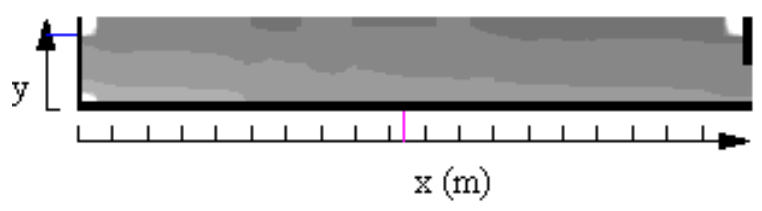

(b)

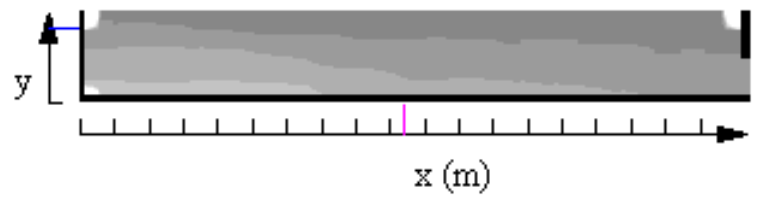

(c)

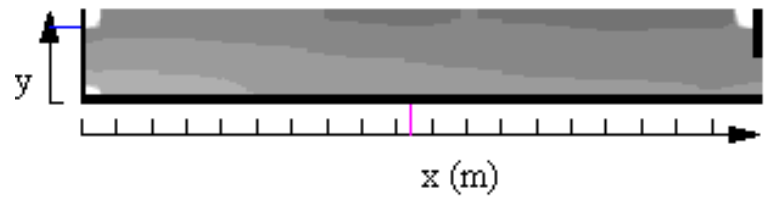

(d)

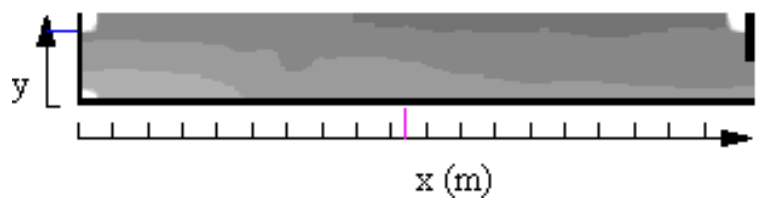

(e)

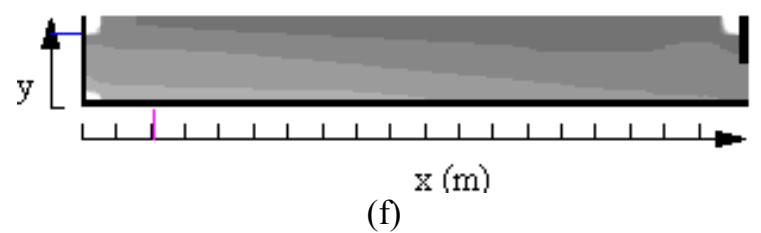

Figure 7 Temperature Fields

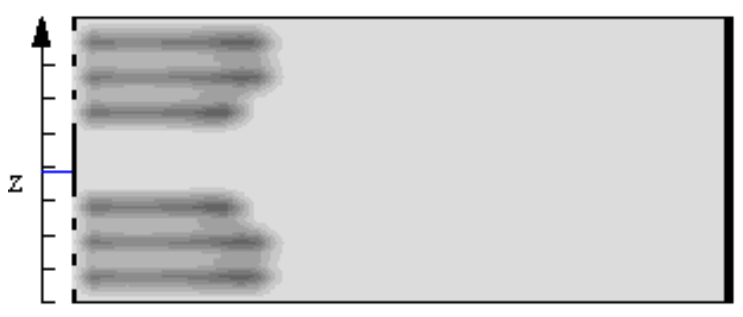

(a)

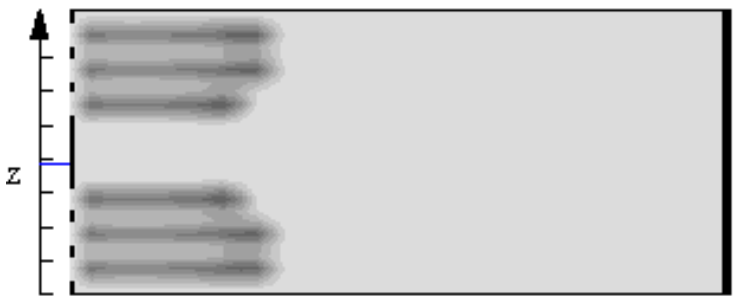

(b)

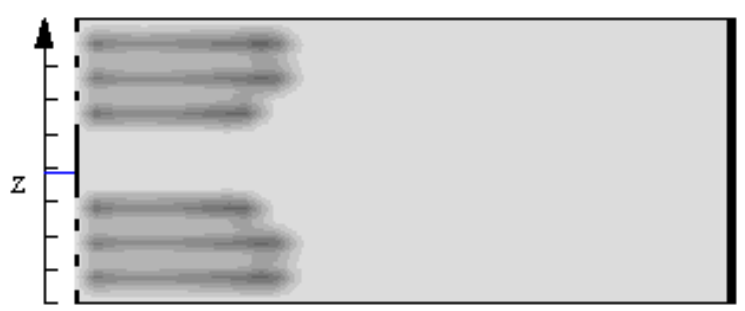

(c)

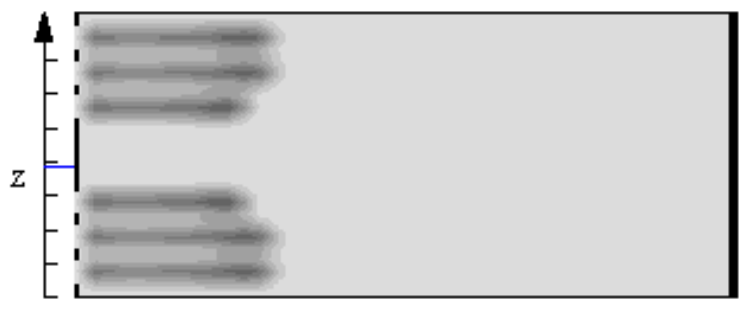

(d)

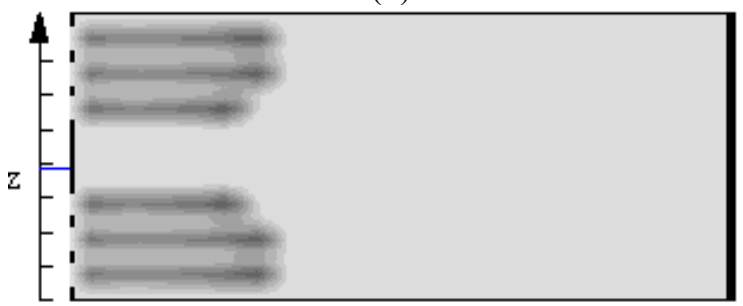

(e)

Figure 8 batch Melting Rate Distribution

\section{CONCLUSIONS}

An electric boosting model was developed and included in a multiphase CFD code for the simulation of flows in a glass melter. The effects of electrical boosting on the flow patterns and heat transfer in a glass melter were investigated. The results indicate 
that the locations and spacing of the electrodes have large impacts on the velocity and temperature distributions in the glass melter. With the same amount of total heat input, the batch melting is kept almost the same. This indicates that the electric booster can be used to replace part of heat by combustion. Therefore, temperature is lower in the combustion space and the life of the furnace can be prolonged. The electric booster can also be used to increase the productivity without increase the furnace size.

\section{ACKNOWLEDGMENTS}

This work was supported by U.S. Department of Energy, Office of Energy Efficiency and Renewable Energy and the Office of Industrial Technology, under Contract W-31-109-ENG-38. The authors would also like to acknowledge the contributions from the members of the consortium: Techneglas, Owens-Corning, Libbey, Inc., Osram-Sylvania, Visteon, Purdue University, and Mississippi State University.

\section{REFERENCES}

Chang, S.L., B. Golchert, and M. Petrick, "Numerical Analysis of CFD-Coupled Radiation Heat Transfer in A Glass Furnace," No. 12084, Proceedings of the $34^{\text {th }}$ National Heat Transfer Conference, Pittsburgh, Penn. (August 20-22, 2000).

Chang, S.L., C.Q. Zhou, B. Golchert, and M. Petrick, "Simulation of Multi-phase Glass-Melt Flows in a Glass Melter," HTD-24235:1-8, Proceedings of 2001 International Mechanical Engineering Congress and Exposition, New York, NY (November 11-16, 2001).

Cook, R.L., R. Arunkumar, and O. P. Norton, "Sensors for a Coupled Combustion Space-Glass Bath Furnace," The Glass Researcher, Vol. 10, Number 1 (2000)

Golchert, B., S.L. Chang, M. Petrick, and C.Q. Zhou "Validation of the Combustion Space Simulation of a Glass Furnace Model," HTD-24230:1-8, Proceedings of 2001 International Mechanical Engineering Congress and Exposition, New York, NY (November 11-16, 2001).

Golchert, B., C.Q. Zhou, S.L. Chang, and M. Petrick, "Investigation of Spectral Radiation Heat Transfer and NOx Emission In a Glass Furnace," HTD-Vol.367:115122, International Mechanical Engineering Congress and Exposition, Orlando, Fl. (November 5-10, 2000).

Hoke, Bryan C., and Robert D. Marchiando, "Using Computational Fluid Dynamics Models to Assess Melter Capacity Changes when Converting to Oxy-Fuel," Proceedings of 18th International Congress on Glass, San Francisco, Cal. (July 1998).

Kawachi, Shinji, and Yoshio Iwatsubo, "Diagnosis and Treatment of Bubbles in Glass Production Using a Numerical Simulator," Glastech. Ber. Glass Sci. Technology, Vol. 72, No. 7, 207-213 (1999).

May, F., and H. Kremer, "Mathematical Modeling of Glass Melting Furnace Design with Regard to NOx Formation," Glastech. Ber. Glass Sci. Technol. 72, No.1 (1999).
Viskanta, R., "Review of Three-Dimensional Mathematical Modeling of Glass Melting," Journal of Non-Crystalline Solids, 177:347-362 (1994).

Patankar, S.V., "Numerical Heat Transfer and Fluid Flow," Hemisphere, Washington, D.C. (1980).

Schnepper, Carol, Benjamin Jurcik, Christel Champinot, and Jean-Francois Simon, “ Coupled Combustion Space-Glass Bath Modeling of a Float Glass Melting Tank Using Full Oxy- Combustion," Proceedings of the Fifth International Conference on the Advances in Fusion and Processing of Glass, Toronto, Canada (July 27-31, 1997).

Stanek, S., "Electrick Melting of Glasses", Elsevier Scientific Publing Company, New York (1977)

The submitted manuscript has been created by the University of Chicago as Operator of Argonne National Laboratory ("Argonne") under Contract No. W-31-109-ENG-38 with the U.S. Department of Energy. The U.S. Government retains for itself, and others acting on its behalf, a paid-up, nonexclusive, irrevocable worldwide license in said article to reproduce, prepare derivative works, distribute copies to the public, and perform publicly and display publicly, by or on behalf of the Government. 